Case Report

\title{
Diabetic Mastopathy: An Uncommon Complication of Diabetes Mellitus
}

\author{
R. X. Kirby, ${ }^{1}$ D. I. Mitchell, ${ }^{1}$ N. P. Williams, ${ }^{2}$ D. A. Cornwall, ${ }^{3}$ and S. O. Cawich ${ }^{1}$ \\ ${ }^{1}$ Department of Surgery, Radiology, Anaesthesia and Intensive Care, University of the West Indies, Mona, Kingston 7, Jamaica \\ ${ }^{2}$ Department of Pathology, University of the West Indies, Mona, Kingston 7, Jamaica \\ ${ }^{3}$ Section of Radiology, Department of Radiology, Anaesthesia, Surgery and Intensive Care, University of the West Indies, Mona, \\ Kingston 7, Jamaica
}

Correspondence should be addressed to S. O. Cawich; socawich@hotmail.com

Received 13 May 2013; Accepted 17 June 2013

Academic Editors: S. Bhatt, T. Çolak, P. De Nardi, and O. Olsha

Copyright (c) 2013 R. X. Kirby et al. This is an open access article distributed under the Creative Commons Attribution License, which permits unrestricted use, distribution, and reproduction in any medium, provided the original work is properly cited.

\begin{abstract}
Introduction. Whilst most consequences of diabetes mellitus are well recognized, breast-related complications remain obscure. The term diabetic mastopathy (DMP) attempts to describe the breast-related consequences of diabetes. Methods. We report the clinicopathologic findings in a patient with DMP and review the literature on this uncommon entity. Results. A 33-year-old woman with type 1 diabetes had excision biopsy of a $2 \mathrm{~cm}$ breast lump. Histopathologic evaluation revealed classic features of DMP: parenchymal fibrosis; keloid-like hyalinization of interlobular stroma; adipose tissue entrapment; lobular compression; dense chronic inflammatory cell infiltration; and lymphoid follicle formation. Conclusion. Clinicians should be aware of DMP as a differential for breast disease in women with uncontrolled diabetes.
\end{abstract}

\section{Introduction}

Whilst most consequences of diabetes mellitus are well recognized, breast-related complications remain obscure. The term diabetic mastopathy (DMP) attempts to describe one of the breast-related consequences of diabetes mellitus. To our knowledge, this is the first report of DMP encountered in the Anglophone Caribbean.

\section{Case Report}

A 33-year-old woman with type I diabetes mellitus noted the presence of a nontender mass in the left breast that had been slowly increasing in size over a six-month period. Although she claimed compliance to insulin since being diagnosed with type I diabetes mellitus at age 15 , there was objective evidence of poor endocrine control. Her history revealed a diagnosis of diabetic retinopathy and several $\mathrm{HbA}_{1 c}$ values $>8.0 \%$ in the 24-month period prior to her presentation. There were no high risk factors for breast cancer.

Clinical examination revealed a $2 \mathrm{~cm}$ nontender lump in the upper outer quadrant of the left breast. The mass was firm, mobile, and not associated with any skin or nipple changes. There was no associated lymphadenopathy, and the contralateral breast was normal on palpation.

Breast ultrasonography revealed an ill-defined mass with strong posterior acoustic shadowing (Figure 1). Ultrasound guided core needle biopsy revealed no evidence of atypical cells but the yield was insufficient for diagnosis. Therefore, an excision biopsy was performed under local anaesthesia.

The excised mass was firm and irregular with a solid white cut surface on gross inspection (Figure 2). Microscopic examination revealed breast tissue with no evidence of malignancy. However, there was marked fibrosis and keloidlike hyalinization of the interlobular stroma (Figure 3), with entrapment of adipose tissue and compression of the ducts and lobules (Figure 4). In addition, there was a dense chronic periductal and perilobular inflammatory cell infiltration, associated with lymphoid follicle formation (Figure 5). These features are pathognomonic for DMP.

With a diagnosis of DMP, no further surgical management was deemed necessary. We continued regular breast surveillance with 6 monthly clinical evaluations and advised regular mammographic screening starting at the age of 40 


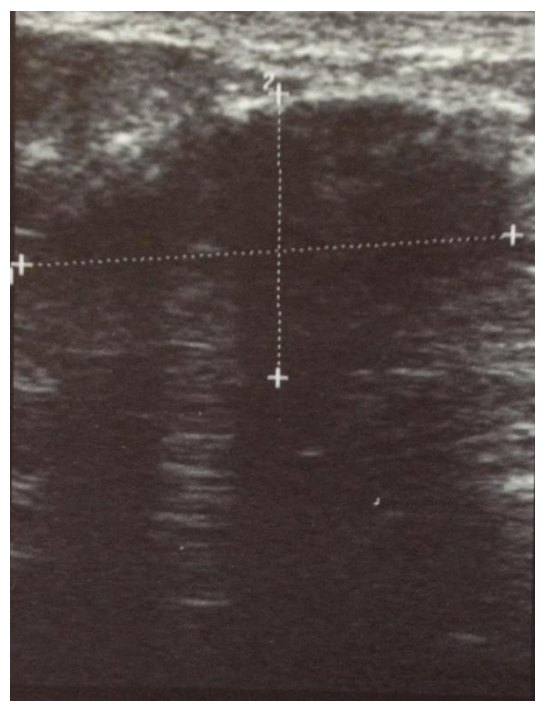

FIGURE 1: Ultrasonogram showing dense posterior acoustic shadowing of the lesion.

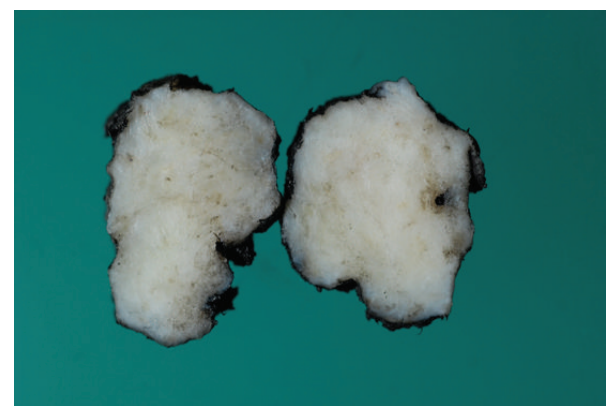

Figure 2: Excised breast mass cut to reveal the homogenous white fibrous parenchyma.

years. At two years follow-up, there has been no recurrence of this lesion, and breast examinations have been normal to date.

\section{Discussion}

In 1984, Soler and Khardori [1] reported on a series of 12 women with longstanding type I diabetes mellitus and breast masses that mimicked cancer clinically but were benign on histological assessment. The term "diabetic mastopathy" was coined to describe these lesions, characterized by marked fibrosis and lymphocytic infiltrates [2].

To the best of our knowledge, this is the first report of DMP from the Caribbean region. It is an important differential to consider in young women with breast disease, especially in the Caribbean where the prevalence of diabetes mellitus is $15.7 \%$ among unselected women [3].

DMP has an incidence that ranges from $0.06 \%$ to $0.34 \%$ $[4,5]$ of benign breast lesions in unselected populations [4$6]$. It has a weak association with type 2 diabetes and thyroid disease [1,7-9] but a more robust relationship with insulindependent diabetes in premenopausal women $[1,4,6]$. The

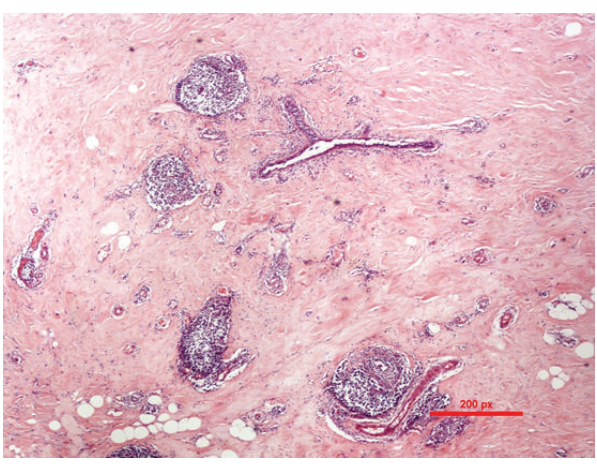

FIGURE 3: Microscopic images showing marked fibrosis and keloidlike hyalinization of interlobular stroma.

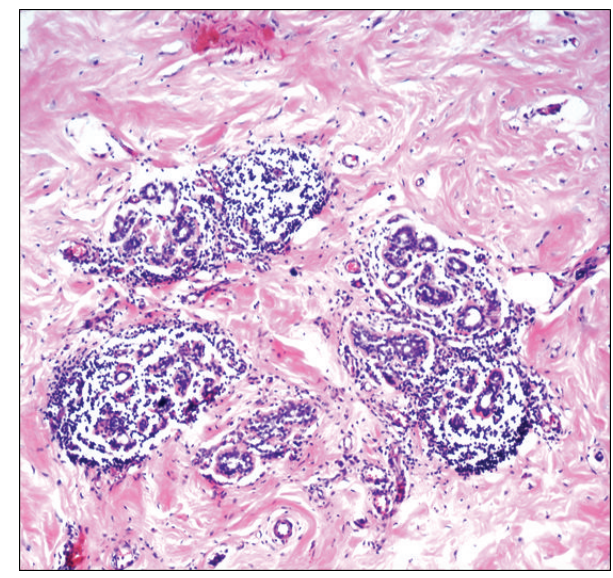

FIGURE 4: Microscopic images showing interlobular fibrosis with entrapped breast lobules and intralobular lymphocytic infiltration $(\mathrm{H} / \mathrm{E} \times 350)$.

entity is diagnosed in $13 \%$ of these women [5], usually after living with type 1 diabetes for more than a decade $[8,9]$.

The majority of patients with DMP have poorly controlled diabetes. By the time breast disease manifests, between $75 \%$ and $80 \%[6,8]$ of patients have already developed retinopathy, neuropathy, or nephropathy $[1,6,8,10]$. This case was typical, occurring in a premenopausal woman, living with type 1 diabetes for 18 years with poor control as evidenced by the presence of diabetic retinopathy and serially elevated $\mathrm{HBA}_{\mathrm{lc}}$ values.

Although the pathogenesis of DMP remains unsettled, the prevailing theories hold a prolific inflammatory response as the underlying pathophysiologic mechanism. There are several proposed inflammatory stimuli, including glycosylated native collagen in the breast parenchyma [7], deposition of glycosylated end products that act as neoantigens [6, $11]$, underlying autoimmune disease $[1,12]$, antibody crossreactivity to exogenous insulin [13] or insulin contaminants [14], and altered tissue degradation due to locoregional cytokine imbalances $[6,7]$. While debate continues about the inciting stimulus, the remaining pathophysiologic mechanisms are better understood. The chronic inflammatory process brings increased collagen deposition, potentiated 


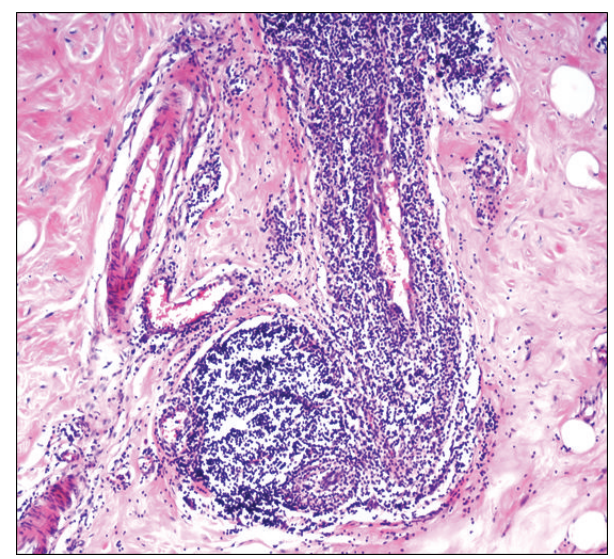

FIGURE 5: Microscopic images showing dense perivascular infiltrate with lymphoid follicle formation $(\mathrm{H} / \mathrm{E} \times 350)$.

collagen cross-linking, extracellular matrix expansion, and impaired cellular senescence. Simultaneously, there is infiltration of lymphocytes that drive the immune response, influx of macrophages, and deposition of other chronic inflammatory cells $[6,7]$.

The end result is a hard, irregular, nontender lump in diffusely thickened breast parenchyma no associated axillary lymphadenopathy $[6,15]$. The lesions tend to be subareolar in location $[8,15,16]$ and are bilateral in $20 \%-60 \%$ of cases $[8,16]$.

Imaging studies do not show any specific features of DMP [17]. However, there is usually a discrete mass with marked acoustic shadowing on ultrasonograms $[4,18]$ and homogenously dense glandular tissue without architectural distortion or microcalcification on mammograms [4]. Magnetic resonance imaging (MRI) may reveal nonspecific stromal enhancement without an enhancing mass. Although this differs from the enhancing focal masses with irregular margins that may be seen on MRI with carcinomas [19-21], the changes are not pathognomonic of DMP. There is usually increased focal uptake of 18-flourodeoxyglucose on PET-CT scans [22] but this is also a nonspecific finding.

After thorough clinical and radiologic assessment, it is still difficult to differentiate DMP and breast carcinoma. The definitive diagnosis hinges on histologic assessment. Fine needle aspiration is not recommended because there is usually firm resistance to needle passes, making sampling difficult [16]. Moreover, there is insufficient cellular yield for diagnostic purposes in 50\%-70\% [4,5] of cases. Core biopsy is the investigation of choice as it has better diagnostic yield than fine needle aspiration and avoids open biopsies $[6,15]$.

Histologic examination usually reveals firm, homogenous, white lesions that are indistinctly separated from surrounding normal breast tissue [23]. Microscopically, there is marked fibrosis with lymphocytes seen around the ducts, lobules, and vasculature [2]. Many of the fibroblasts undergo epithelioid change [6]. Although we note exceptions in few cases $[8,24]$, the findings generally considered to be pathognomonic for DMP include epithelioid fibroblasts set in a dense fibrous stroma as described by Tomaszewski et al.
[7]; keloidal fibrosis (thick fibrous bands replacing $>5 \mathrm{~mm}$ of parenchyma) as defined by Seidman et al. [9]; and the classic lymphocytic ductitis/lobulitis reported by Schwartz and Strauchen [11]. These pathognomonic microscopic features were all present in this case.

Traditionally, DMP has been considered a benign disease $[4,6,8,25,26]$. The four largest series in medical literature [4, $6,8,25]$ evaluated a combined cohort of 71 patients followed over a period of 6-14 years $[4,8]$. There were no recorded instances of malignant transformation in these patients. Based on this data, many authorities recommend observation over surgical treatment since DMP is not considered a premalignant lesion $[4,6,8,15,25,26]$. The recommendations were reinforced by the propensity for extensive local recurrence after excision biopsy in $42 \%-80 \%$ of cases within 5 years [ 6 , 8]. Often the recurrences are bilateral, involving extensively more breast tissue than the original lesion. This may incite management dilemmas [27].

The medical literature contains four case reports documenting instances where DMP and ductal carcinoma coexist in the same breast [28-31]. This reinforces the need for exhaustive clinicopathological evaluation and a high index of suspicion.

\section{Conclusion}

Diabetic mastopathy is an uncommon lesion, but clinicians should be aware of this entity in the Caribbean where there is a high prevalence of diabetes mellitus.

\section{References}

[1] N. G. Soler and R. Khardori, "Fibrous disease of the breast, thyroiditis, and cheiroarthropathy in type I diabetes mellitus," The Lancet, vol. 1, no. 8370, pp. 193-195, 1984.

[2] B. F. Byrd Jr., W. H. Hartmann, L. S. Graham, and H. H. Hogle, "Mastopathy in insulin-dependent diabetics," Annals of Surgery, vol. 205, no. 5, pp. 529-532, 1987.

[3] R. Wilks, C. Rotimi, F. Bennett et al., "Diabetes in the Caribbean: results of a population survey from Spanish Town, Jamaica," Diabetic Medicine, vol. 16, no. 10, pp. 875-883, 1999.

[4] W. W. Logan and N. Y. Hoffman, "Diabetic fibrous breast disease," Radiology, vol. 172, no. 3, pp. 667-670, 1989.

[5] F. E. Gump and J. McDermott, "Fibrous disease of the breast in juvenile diabetes," New York State Journal of Medicine, vol. 90, no. 7, pp. 356-357, 1990.

[6] P. M. Camuto, E. Zetrenne, and T. Ponn, "Diabetic mastopathy: a report of 5 cases and a review of the literature," Archives of Surgery, vol. 135, no. 10, pp. 1190-1193, 2000.

[7] J. E. Tomaszewski, J. S. J. Brooks, D. Hicks, and V. A. Livolsi, "Diabetic mastopathy: a distinctive clinicopathologic entity," Human Pathology, vol. 23, no. 7, pp. 780-786, 1992.

[8] K. A. Ely, G. Tse, J. F. Simpon, R. Clarfeld, and D. L. Page, "Diabetic mastopathy: a clinicopathologic review," American Journal of Clinical Pathology, vol. 113, no. 4, pp. 541-545, 2000.

[9] J. D. Seidman, L. A. Schnaper, and L. E. Phillips, "Mastopathy in insulin-requiring diabetes mellitus," Human Pathology, vol. 25, no. 8, pp. 819-824, 1994.

[10] M. C. Morgan, M. G. Weaver, J. P. Crowe, and F. W. AbdulKarim, "Diabetic mastopathy: a clinicopathologic study in 
palpable and nonpalpable breast lesions," Modern Pathology, vol. 8, no. 4, pp. 349-354, 1995.

[11] I. S. Schwartz and J. A. Strauchen, "Lymphocytic mastopathy. An autoimmune disease of the breast?" American Journal of Clinical Pathology, vol. 93, no. 6, pp. 725-730, 1990.

[12] G. A. Lammie, L. G. Bobrow, M. D. M. Staunton, D. A. Levison, G. Page, and R. R. Millis, "Sclerosing lymphocytic lobulitis of the breast-evidence for an autoimmune pathogenesis," Histopathology, vol. 19, no. 1, pp. 13-20, 1991.

[13] K. Miura, C. Teruya, N. Hatsuko, and H. Ogura, "Autoantibody with cross-reactivity between insulin and ductal cells may cause diabetic mastopathy: a case study," Case Reports in Medicine, vol. 2012, 5 pages, 2012.

[14] J. D. Seidman, L. A. Schnaper, and L. E. Phillips, "Mastopathy in insulin-requiring diabetes mellitus," Human Pathology, vol. 25, no. 8, pp. 819-824, 1994.

[15] Z. Cooper and M. P. McKay, "Diabetic mastopathy," American Journal of Emergency Medicine, vol. 22, no. 6, p. 498, 2004.

[16] S. D. Rollins, "Fine-needle aspiration cytology of diabetic fibrous mastopathy," Diagnostic Cytopathology, vol. 9, no. 6, pp. 687-690, 1993.

[17] Y. Sakuhara, T. Shinozaki, Y. Hozumi, S. Ogura, K. Omoto, and M. Furuse, "MR imaging of diabetic mastopathy," American Journal of Roentgenology, vol. 179, no. 5, pp. 1201-1203, 2002.

[18] C. Cole Beuglet, R. Z. Soriano, A. B. Kurtz, and B. B. Goldberg, "Ultrasound analysis of 104 primary breast carcinomas classified according to histopathologic type," Radiology, vol. 147, no. 1, pp. 191-196, 1983.

[19] K. T. Wong, G. M. K. Tse, and W. T. Yang, "Ultrasound and MR imaging of diabetic mastopathy," Clinical Radiology, vol. 57, no. 8, pp. 730-735, 2002.

[20] P. Balan and L. W. Turnbull, "Dynamic contrast enhanced magnetic resonance imaging and magnetic resonance spectroscopy in diabetic mastopathy," Breast, vol. 14, no. 1, pp. 68-70, 2005.

[21] I. Isomoto, T. Wada, K. Abe, and M. Uetani, "Diagnostic utility of diffusion-weighted magnetic resonance imaging in diabetic mastopathy," Clinical Imaging, vol. 33, no. 2, pp. 146-149, 2009.

[22] R. Gurion, D. Groshar, A. Schnidel, O. Shpilberg, and P. Raanani, "18F-fluorodeoxyglucose-avid mammary mass in a patient with insulin-dependent diabetes Mellitus and Hodgkin's lymphoma: relapse or Pitfall?" Israel Medical Association Journal, vol. 8, no. 12, pp. 838-839, 2006.

[23] S. Boullu, L. Andrac, L. Piana, P. Darmon, A. Dutour, and C. Oliver, "Diabetic mastopathy, complication of type 1 diabetes mellitus: report of two cases and a review of the literature," Diabetes and Metabolism, vol. 24, no. 5, pp. 448-454, 1998.

[24] M. A. Ashton, M. Lefkowitz, and F. A. Tavassoli, "Epithelioid stromal cells in lymphocytic mastitis-a source of confusion with invasive carcinoma," Modern Pathology, vol. 7, no. 1, pp. 49-54, 1994.

[25] R. Valdez, J. Thorson, W. G. Finn, B. Schnitzer, and C. G. Kleer, "Lymphocytic mastitis and diabetic mastopathy: a molecular, immunophenotypic, and clinicopathologic evaluation of 11 cases," Modern Pathology, vol. 16, no. 3, pp. 223-228, 2003.

[26] R. Lakshmanan, M. J. Clarke, and T. C. Putti, "Diabetic fibrous mastopathy," Singapore Medical Journal, vol. 48, no. 6, pp. 579581, 2007.

[27] Y. C. Kudva, C. Reynolds, T. O’Brien et al., “'Diabetic mastopathy', or sclerosing lymphocytic lobulitis, is strongly associated with type 1 diabetes," Diabetes Care, vol. 25, no. 1, pp. 121-126, 2002.
[28] M. Yamashita, T. Ogawa, N. Hanamura et al., "An uncommon case of Tlb breast cancer with diabetic mastopathy in type II diabetes mellitus," Breast Cancer, vol. 20, no. 1, pp. 92-96, 2013.

[29] E. P. Y. Fung, K. F. Tam, L. Allen, W. F. Yuen, J. Lo, and J. C. S. Chan, "A case of breast cancer with diabetic mastopathy: radiological and pathological correlation," Journal of the Hong Kong College of Radiologists, vol. 7, no. 3, pp. 137-139, 2004.

[30] H. A. Gabriel, C. Feng, E. B. Mendelson, and S. Benjamin, "Breast MRI for cancer detection in a patient with diabetic mastopathy," American Journal of Roentgenology, vol. 182, no. 4, pp. 1081-1083, 2004.

[31] S. P. Mackey, S. Sinha, J. Pusey, Y. Chia, and G. A. D. McPherson, "Breast carcinoma in diabetic mastopathy," Breast, vol. 14, no. 5, pp. 392-398, 2005. 


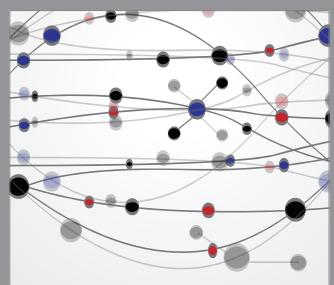

The Scientific World Journal
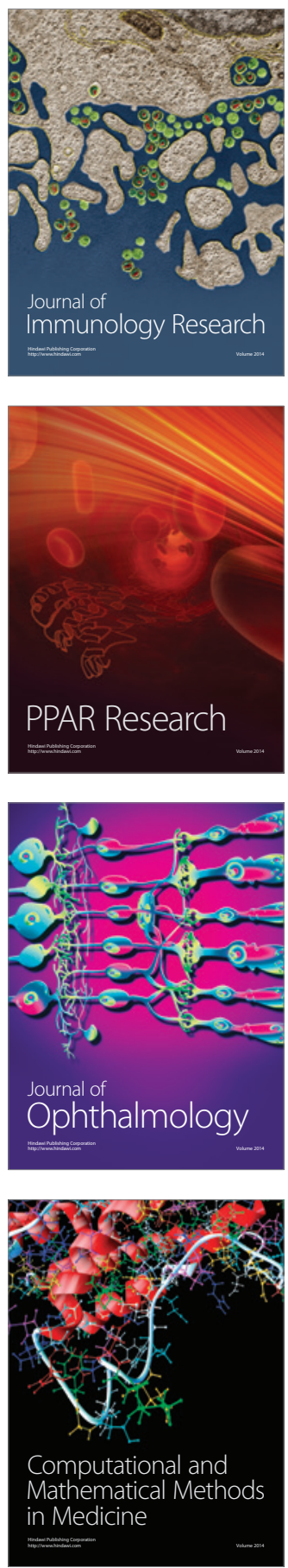

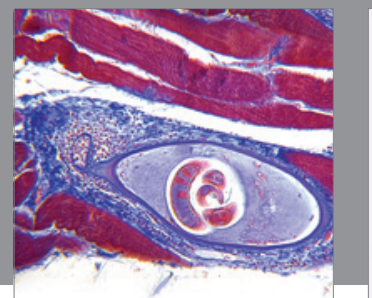

Gastroenterology

Research and Practice
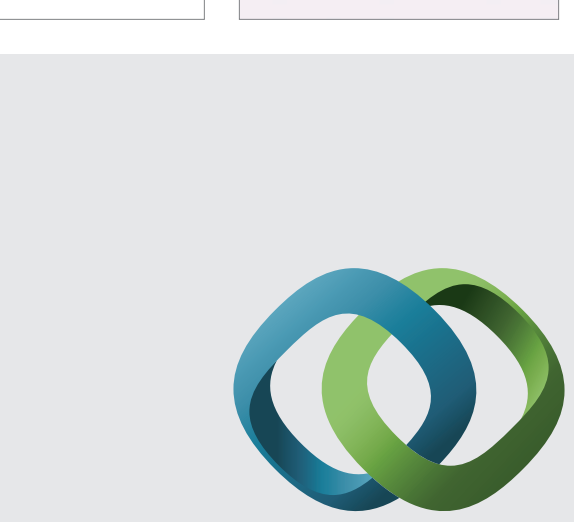

\section{Hindawi}

Submit your manuscripts at

http://www.hindawi.com
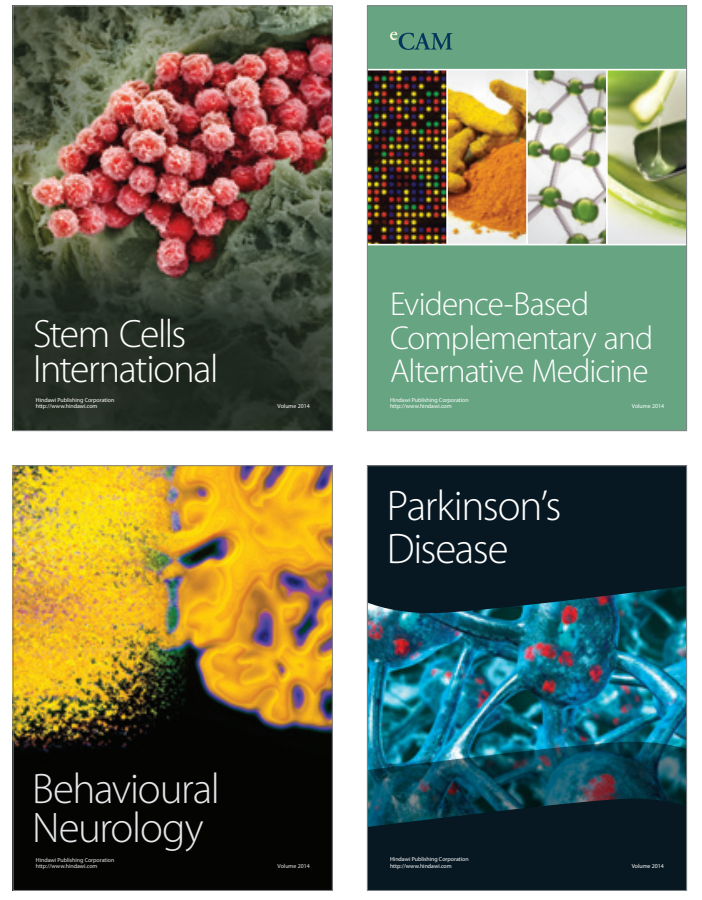
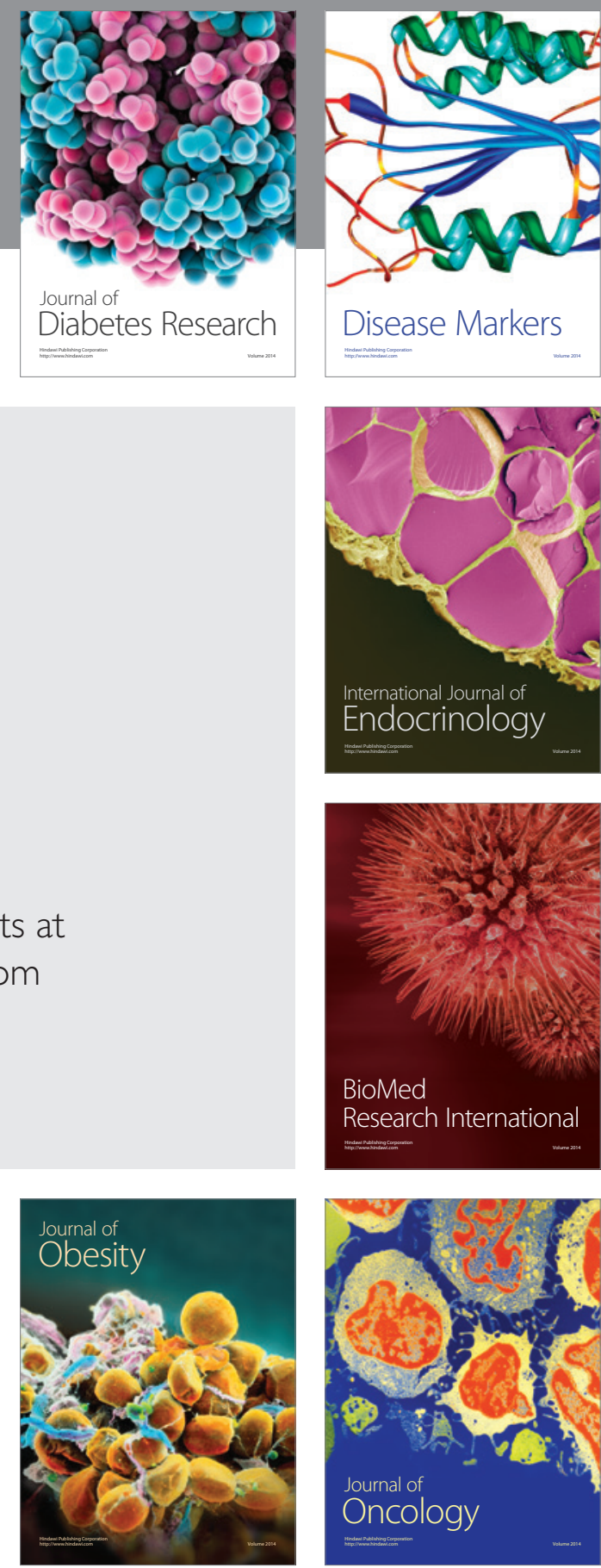

Disease Markers
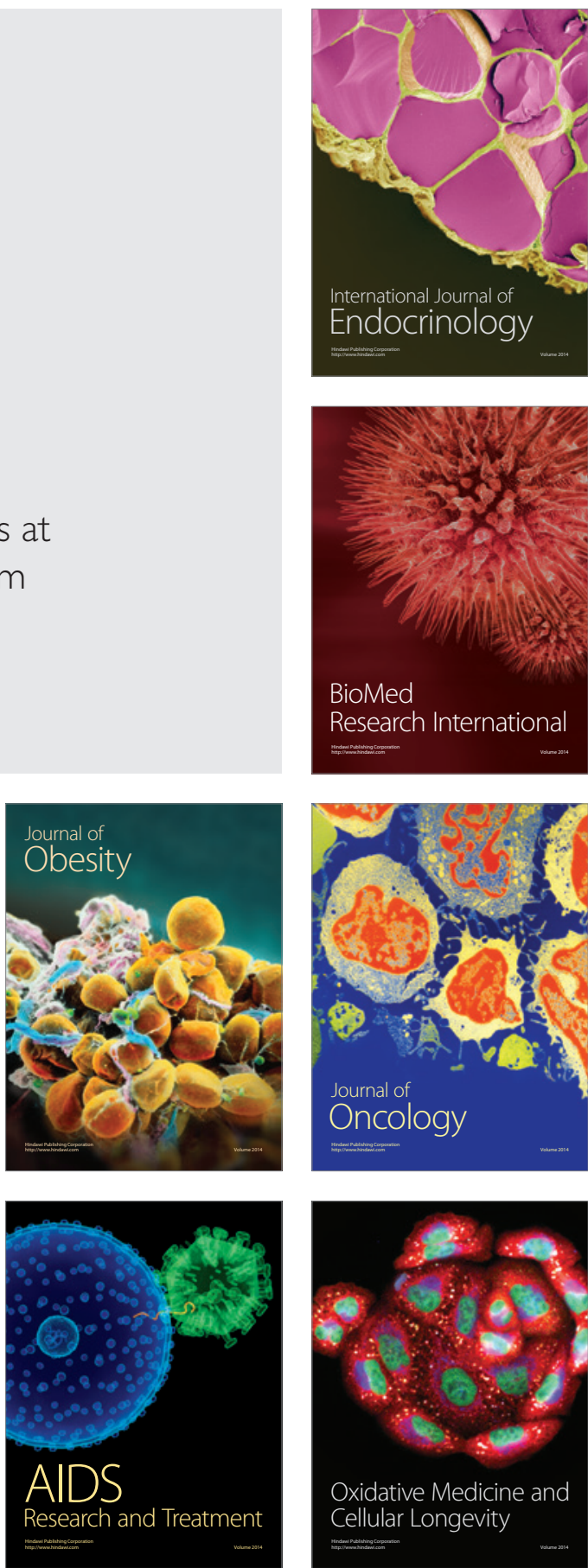